\title{
A multi-step assembly process: drawing, flanging and hemming of metallic sheets
}

\author{
P.Y. Manach ${ }^{1, a}$, N. Le Maoût ${ }^{1}$, and S. Thuillier ${ }^{1}$ \\ LIMATB, Université de Bretagne-Sud, 56321 Lorient, France
}

\begin{abstract}
This paper presents hemming tests on complex geometries, combining curved surfaces and radii of curvature in the plane. The samples are firstly prestrained in order to obtain a strain history prior to flanging and hemming. The choice of the sample geometries as well as prior plastic strains is based on a survey of current geometries hemmed in automotive doors. A device has been designed to hem these samples both by classical and roll-hemming processes and to allow a comparison between both technologies. Roll-in, which characterizes the change of geometry of the hemmed zone between flanging and hemming, and loads are obtained during this multistep process. Results show that roll-in observed in roll-hemming is lower than in classical hemming and that its evolution greatly differs between the two processes. The analysis of the results on different samples shows that it is difficult to establish rules on the variation of other parameters in such a complex multistep process and that it requires an intensive use of numerical simulation.
\end{abstract}

\section{Introduction}

Hemming is an assembly process by plastic deformation which consists of bending a small height of a sheet, called the outer part, over another, called the inner part [1]. This assembly method is widely used in the automotive industry for the opening parts of vehicles, to join the outer panel to the reinforcing inner part. The process is usually performed in three steps: flanging, pre-hemming, and hemming (Fig.1). Flanging is the last step of the drawing operation and consists in bending the sheet up to around $90^{\circ}$. Pre-hemming is done after the inner part is placed on the outer part and increases the bending angle to around $135^{\circ}$ to prepare for the next operation. Finally, the hemming tool folds the outer part over the inner skin.

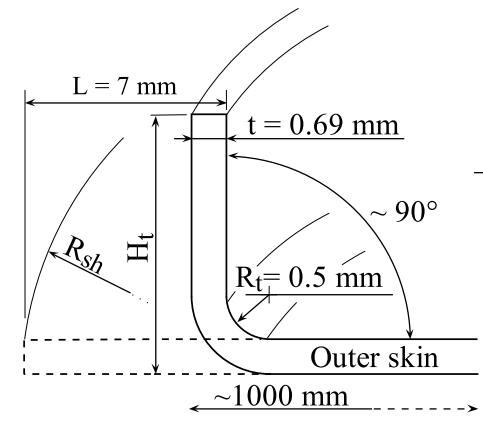

(a)

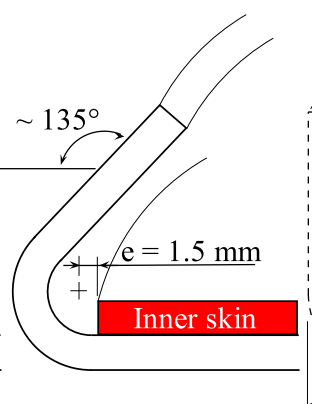

(b)

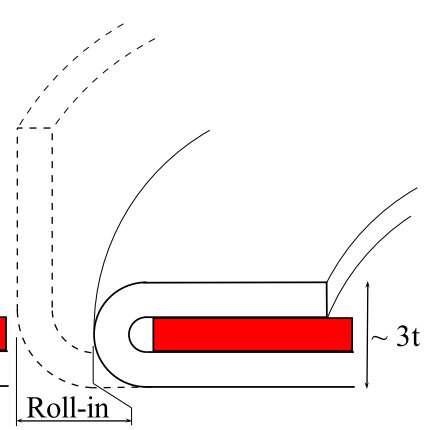

(c)

Fig. 1. Steps of (a) flanging, (b) pre-hemming, and (c) hemming. The characteristic parameters are a flanging height $H_{t}$, a flanging radius $R_{t}, e$ is the position of the inner part. Outer and inner parts have the same thickness $t$

a e-mail: pierre-yves.manach@univ-ubs.fr

This is an Open Access article distributed under the terms of the Creative Commons Attribution-Noncommercial License 3.0, which permits unrestricted use, distribution, and reproduction in any noncommercial medium, provided the original work is properly cited. 
There are two main industrial hemming technologies, the classical hemming process, and the rollhemming process. The former makes use of hemming units situated all around the opening part. Prehemming, and later hemming, blades simultaneously assembly the opening part (Fig.2.a). The latter uses a roller guided by a handling robot along the hemming line [2] (Fig.2.b). The roller, which freely rotates around its revolution axis, pre-hems, then progressively hems the flanged edge of the opening part. The advantage of this method is its very low cost while the main drawbacks are the high process time compared to the very short one of the classical hemming. Despite the difficulties to hem parts with complex geometries, the use of this process has shown a high increase during the five past years [3]. The hemming process generates a modification of the final dimensions of the assembly which is difficult to anticipate. This dimensional reduction, called roll-in, modifies the esthetic of the vehicle because the clearance between the opening part and the body of the vehicle may not remains constant.
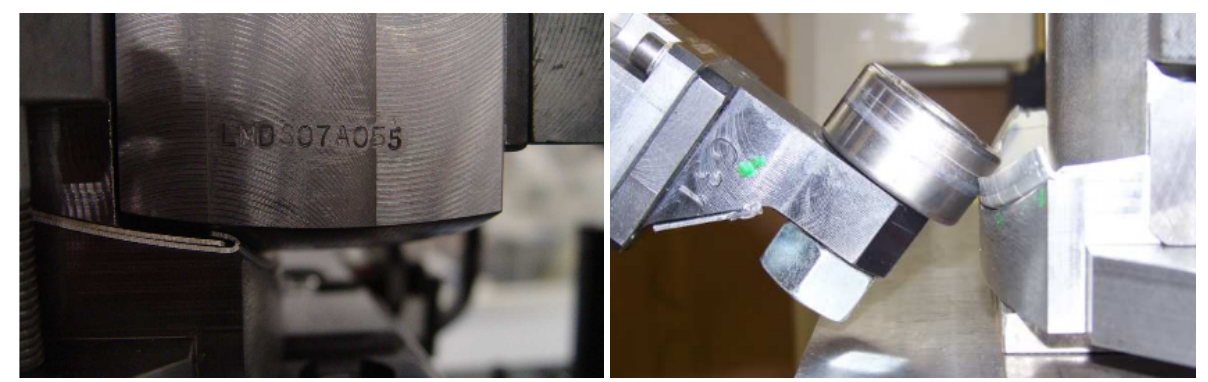

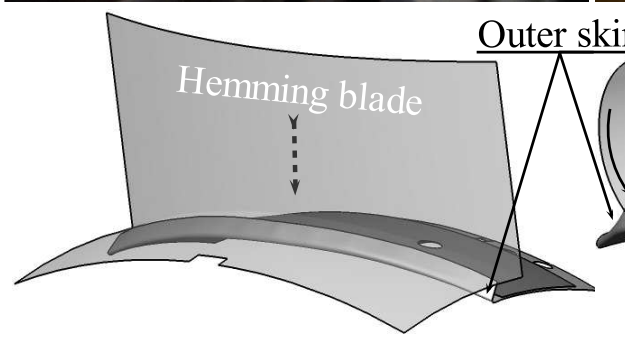

(a) (b)

Fig. 2. Classical (a) and roll-hemming (b) processes

Some studies were carried out with classical hemming on planar geometries which do not always reflect reality because the testing protocol does not let one reproduce the strain history of a sheet in an industrial context [4]. In this study, a series of tests is performed to hem samples with more complex geometries and strain histories than planar straight edged ones. To study the influence of geometry and the state of pre-strain on roll-in and load, as well as to build a reference for comparison with the numerical simulation, this investigation gathers experimental data on the hemming of concave or convex hemmed-edge curved surface samples. An experimental set-up has been designed to study both classical and roll-hemming processes. The samples are pre-strained through biaxial tests to obtain a strain geometry and history similar to that of industrial parts. Flanging, pre-hemming, and hemming loads are recorded and geometrical measurements are taken after each step for steels samples.

\section{Material and experiments}

A E220BH steel sheet of $0.69 \mathrm{~mm}$ thickness was studied. The samples are characterized by a curved surface radius $S_{s h}$ (convex) or $S_{s t}$ (concave) and a hemming edge radius $E_{s h}$ (Fig.3). Radii $S_{s h}$ or $S_{s t}$ are obtained by sample pre-strain before the flanging operation, due to the biaxial bulge test set up described in [5]. Laser technology was used to trim the hemming samples to obtain their specific geometry. A radius of $215 \mathrm{~mm}$ for the curved surface is representative of the most frequently areas of automotive opening parts. The radius value $E_{s h}=258 \mathrm{~mm}$ (before flanging) is the same for both 
configurations to evaluate the influence of orientation on the curvature radius.

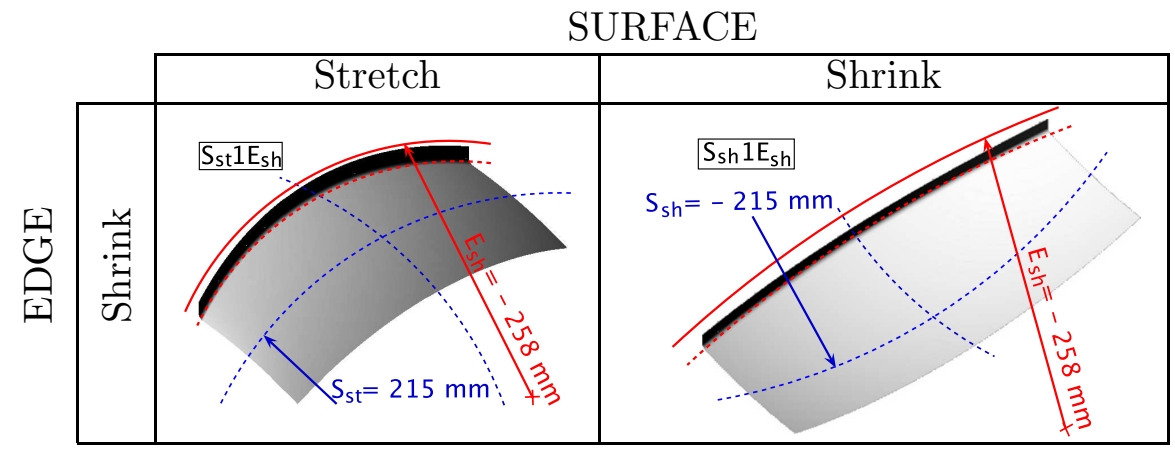

Fig. 3. Classification of studied samples with associated geometrical parameters

Fig.4.a presents the measured sections of the geometry, the one at $0^{\circ}$ corresponds to the rolling direction (RD). The measurements for the flanging height and the opening angle, as well as the roll-in reference, are given in Fig.4.b. Roll-in is calculated by using the distance between the points (1st point and 2 nd point at $3.2 \mathrm{~mm}$ from the surface) as a reference during flanging. For the pre-hemming, and hemming steps, the second point is the one farthest away in the bent zone. $\mathrm{A} \pm 0.02 \mathrm{~mm}$ precision vernier caliper was used to measure the flanging height and the roll-in. The opening angle after flanging was measured with $\mathrm{a} \pm 0.5^{\circ}$ precision protractor.

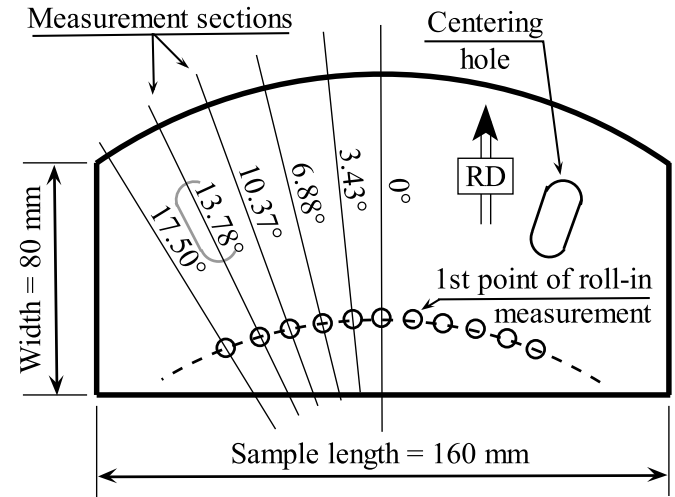

(a)

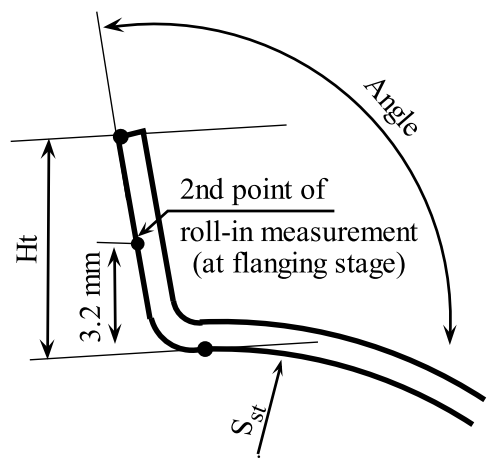

(b)

Fig. 4. Details of the measurements of geometric parameters after springback during the flanging step

A hemming device was designed to hem pre-strained samples [5]. The device fits on a 500-kNcapacity tensile testing machine. The dies are mounted on a guide rail so that horizontal loads can be transmitted to a $\pm 50 \mathrm{kN}$ capacity load sensor. The vertical load on the blades is measured by the load cell of the machine. The flanging die and blank-holder have a flanging radius of $0.5 \mathrm{~mm}$, which allows both configurations, $S_{s h} 1 E_{s h}$ and $S_{s t} 1 E_{s h}$, to be flanged by simply turning the tools over. A removable plate that holds the dies and blank-holders can be taken off for roll-hemming with a robot.

\section{Flanging}

For the flanging operation, the position of the sample on the die is adjusted to have an identical outer edge/die distance at three points (center and centering holes), with a depth gauge. A value of $L=6 \pm$ $0.1 \mathrm{~mm}$ is measured radially, after the application of the blank-holder force. The displacement rate of the blade is $15 \mathrm{~mm} \cdot \mathrm{min}^{-1}$. According to the industrial process, the clearance between the blade and the flanging die is equal to the initial thickness of the sheet augmented by $10 \%$. The blank-holder force is $93 \mathrm{kN}$ and all the tests were carried out without any lubricant. 
(a)

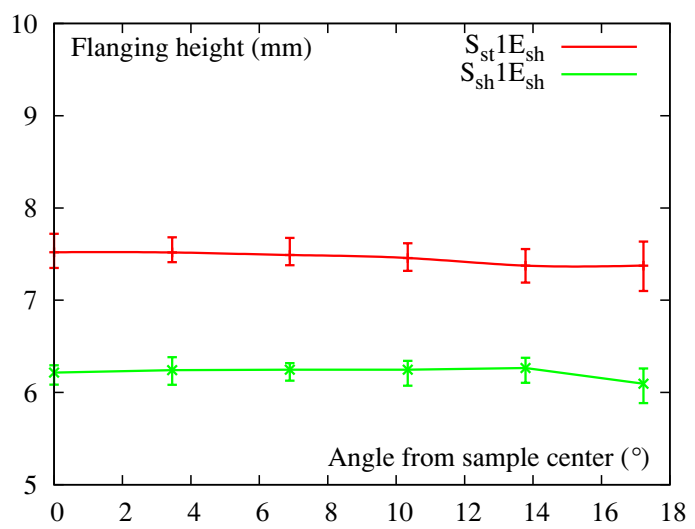

(b)

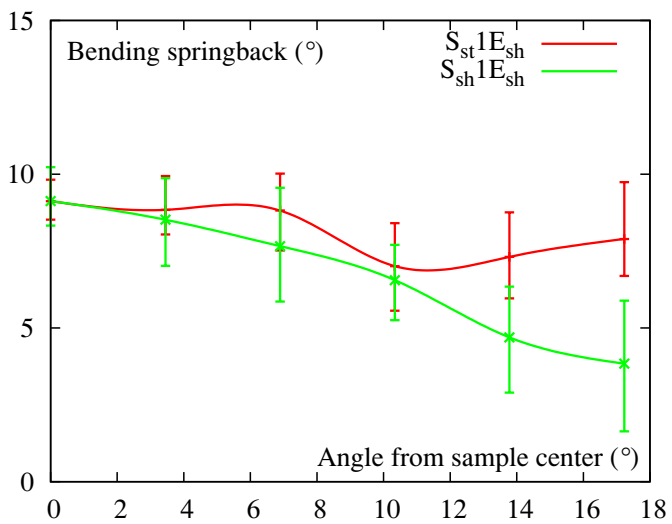

Fig. 5. Measurement of the flanging height (a) and the opening angle (b) after the flanging operation. The curves represent an average of the two halves of the samples plotted on the right side

Fig.5.a shows the flanging height obtained for both configurations. The first point of contact of the measurement is situated at the beginning of the flanging radius and the second at the top of the flanged edge (Fig.1.a). The vertical error bars represent the dispersion of the six tests that were carried out (three samples per hemming technology), uncertainty of measurements, as well as the divergence between the two halves of the sample. For this material, the flanging height is rather constant along the curved edge, but $21 \%$ higher in the case of configuration $S_{s t} 1 E_{s h}$ than $S_{s h} 1 E_{s h}$. Differences are also observed for the opening angles in Fig.5.b. Both configurations present a similar springback evolution, the value of which is more important in the center of the sample and decreases near the free edges. The influence of $S_{s h / s t}$ leads to a large difference on the bending springback of configuration $S_{s h} 1 E_{s h}$ near the free ends.

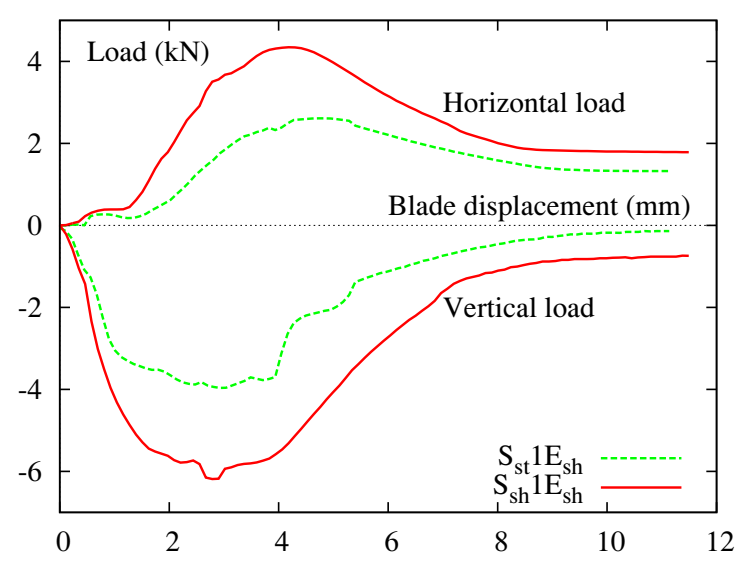

Fig. 6. Evolution of loads obtained during flanging
Fig.6 gives load evolution during flanging. The first load increase corresponds to the folding of the sheet against the radius of the flanging die [6]. The load decrease is linked to bringing the flanged edge closer to the die. Finally the nonzero load at the end of flanging is due to friction between the blade and the sheet [7]. The sign of the loads has been arbitrarily chosen to facilitate the reading of different results on the figure. The vertical loads are higher for the configurations of type $S_{s h}$, The difference between both configurations being about $100 \%$. This observation correlates with a largest sensitivity to wrinkling of these configuration.

\section{Pre-hemming}

The flanged samples are placed in the pre-hemming die in a way that makes them flush with it. The inner skin is placed over the outer skin using the locating holes. The blank-holder force is equal to 62 $\mathrm{kN}$, which corresponds to a pressure of $8.9 \mathrm{MPa}$. The movement of the tools is only vertical and the 
contact surface of the pre-hemming blade with the sheet is inclined at $45^{\circ}$ in relation to the surface of the die. The absence of horizontal movement of the blade prevents the risk of visual defects due to greater deflection of the outer part on the die [8]. The displacement velocity of the mobile plate is $5 \mathrm{~mm} . \mathrm{min}^{-1}$. Fig.7 shows the samples $S_{s h} 1 E_{s h}$ and $S_{s t} 1 E_{s h}$ after pre-hemming. A large distance is observed between the edge of the sample and the blanh-holder, because the hemming dies and blankholders were created to be able to adapt to a classical hemming and roll-hemming work environment.

(a)

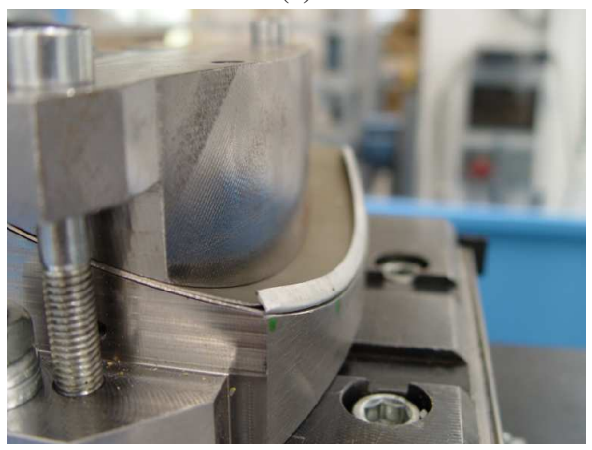

(b)

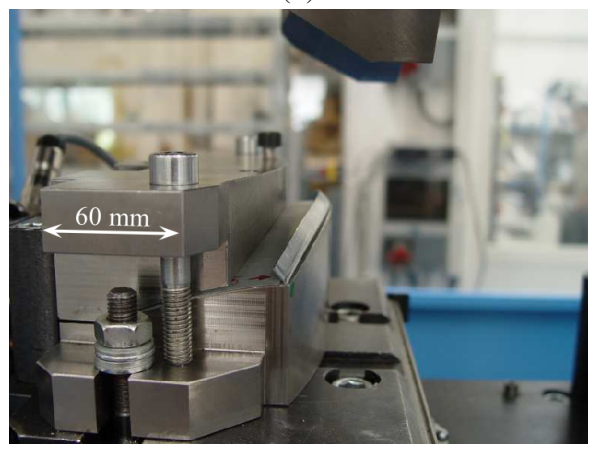

Fig. 7. Pictures of samples (a) $S_{s h} 1 E_{s h}$ and (b) $S_{s t} 1 E_{s h}$ at the end of the pre-hemming operation

For the roll-hemming process the kinematics of the roller is imposed by a handling robot. A $47 \mathrm{~mm}$ cylindrical roller, Fig.2.b is mounted on a ball bearing giving it free rotation on its revolution axis. A sensor, placed above the roller records the compressive loads applied along the direction of the robot arm. A spring placed between the roller and the robot arm helps compensate for difficult passages for the roller, especially in the case of wrinkling. The trajectory of the robot is determined so that the arm is constantly normal to the die surface. The second condition to set up the robot, in the so-called normal way, imposes aligning the roller revolution axis with the radius normal of the hemming edge.

(a)

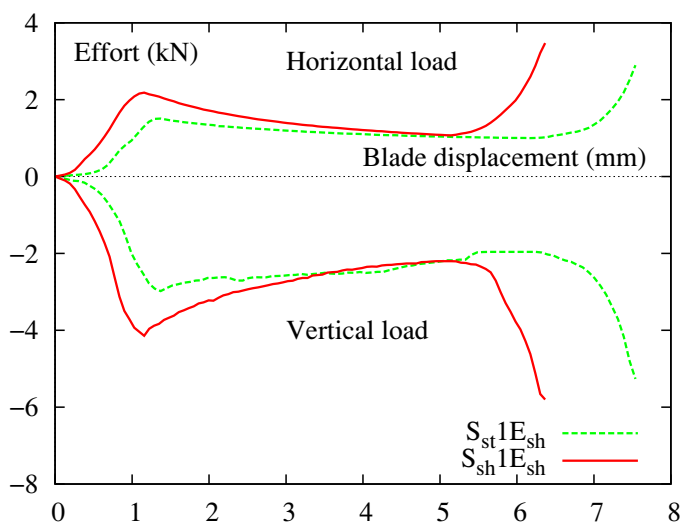

(b)

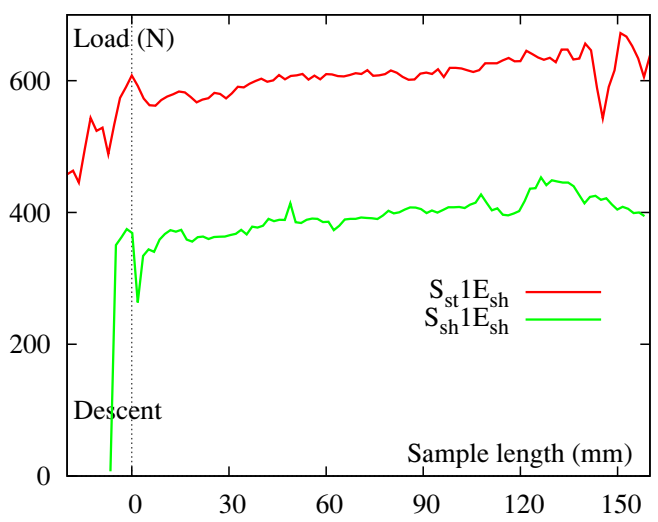

Fig. 8. Load vs blade displacement during pre-hemming for classical (a) and roll-hemming (b) processes

At the beginning of pre-hemming, the roller is positioned on the edge of the die and fold the edge of the sheet. This positioning, called descent of the roller, is similar to the folding of the sheet with a pre-hemming blade with the classical process. The descent is carried out according to the normal to the surface of the die. The linear speed of the roller is $80 \mathrm{~mm} \cdot \mathrm{s}^{-1}$; it is not constant since the speed of the roller is zero after descent and increases to reach the set speed. It has to be noticed that the descent of the roller generates non symmetric large deformations of the free edge of the sample. 
Fig.8.a gives the evolution of pre-hemming loads during classical hemming. The first load increase is linked to the inclination of the edge to $90^{\circ}$ after springback following the flanging step. The load decrease is due to the flexion of the edge around the plastic hinge formed at the level of the flanging radius $[7,8]$. The length of the plateau, expressed through pre-hemming blade displacement, corresponds to the end of the first increase and the beginning of the second load increase. Finally, to obtain a $45^{\circ}$ angle after sprinkback, the blade only presses on the bent zone which leads to a significant load increase. A large difference can be seen over the entire blade displacement. This phenomenon is linked to the difference of flanging height value which is higher for configuration $S_{s t} 1 E_{s h}$ leading to a larger blade displacement to reach the prescribed pre-hemming angle.

Fig.8.b gives the evolution of pre-hemming loads during roll-hemming. The evolution of the load during the descent of the roller is similar to that observed for classical pre-hemming. A first increase is generated by the inclination of the edge, then the load stabilizes. The value of the load during this descent is generated by the crushing of the folded zone. During the progress of the roller, the pre-hemming load is rather constant, of the order of $350 \mathrm{~N}$ for configuration $S_{s h} 1 E_{s h}$ and $600 \mathrm{~N}$ for $S_{s t} 1 E_{s h}$, since this material is not very sensitive to the appearance of wrinkles. Once again, the higher value observed for configuration $S_{s t} 1 E_{s h}$ is due to its higher flanging height.

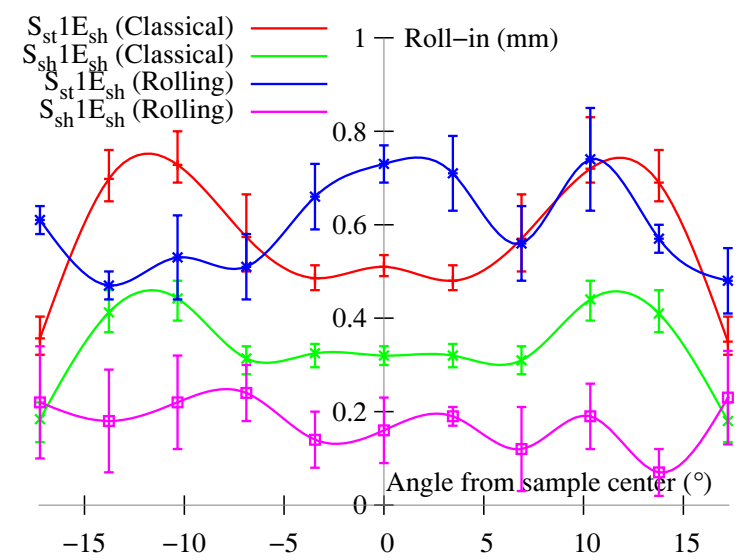

Fig. 9. Evolution of roll-in after classical and roll pre-hemming

Fig.9 presents roll-in measurements at the end of pre-hemming for both processes. Roll-in is lower near the free edges and in the center of the sample. For both hemming processes, it is observed that the orientation of the radius of curvature has a large influence on the value of the roll-in. Configuration $S_{s h} 1 E_{s h}$ presents a lower roll-in than $S_{s t} 1 E_{s h}$ of the order of $43 \%$. The value of $0.35 \mathrm{~mm}$ is rather weak of the order of half the thickness of the sheet. Concerning the roll-hemming process, the roll-in measured for the configuration $S_{s h} 1 E_{s h}$ is on average twice lower than for classical hemming. It remains relatively stable over the length of the sample with nevertheless some significant variations at the ends of the sample, which correspond to the lowering of the rollers. For configuration $S_{s t} 1 E_{s h}$, the average roll-in value is similar for both processes.

\section{Hemming}

Fig.10.a shows the evolution of hemming loads in classical hemming. The maximum displacement of the blade is determined to get a hemmed thickness, before springback, that is three times the initial thickness of the sheet. The first load increase is due to the tilt of the sheet at $45^{\circ}$ after pre-hemming springback. The increase of the distance between the load application point and the bent zone leads to a load decrease to bend the sheet. Finally, the blade greatly presses on the bent zone to obtain the desired thickness of the assembly, which leads to a significant load increase. Furthermore, the end of this step is marked by the roll-out of the sheet, as well as a change in sign of the horizontal load.

Fig.10.b shows the reaction force obtained on the instrumented device during roll-hemming. In order not to cumulate strains due to the descent of the roller both in pre-hemming and in hemming, the path of the roller is reversed between the two stages. This procedure, adopted in most of the industrial projects, allows also the reduction of cycle time by starting the hemming from the position of the roller 
(a)

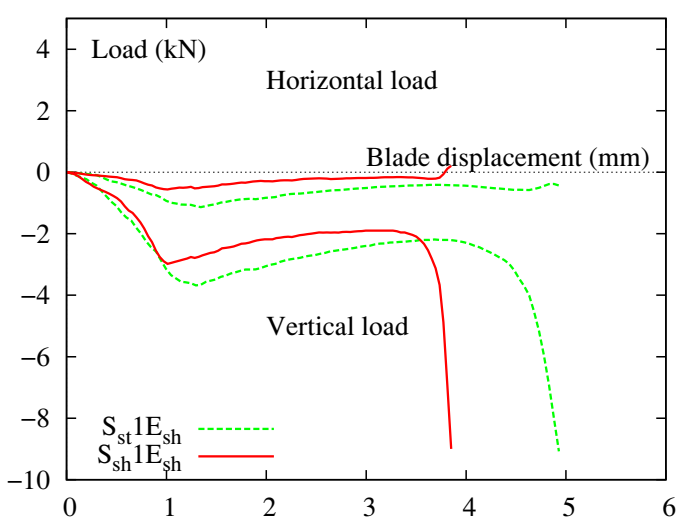

(b)

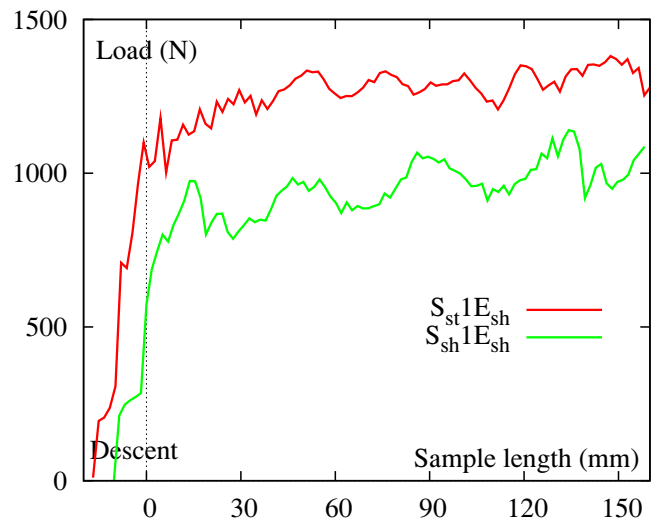

Fig. 10. Load vs blade displacement during hemming for classical (a) and roll-hemming (b) processes

at the end of pre-hemming. The evolution of the load is similar to that observed during pre-hemming, i.e. a higher constant force of $1200 \mathrm{~N}$ for configuration $S_{s t} 1 E_{s h}$ which presents the higher flanging height and of the order of $900 \mathrm{~N}$ for configuration $S_{s h} 1 E_{s h}$.

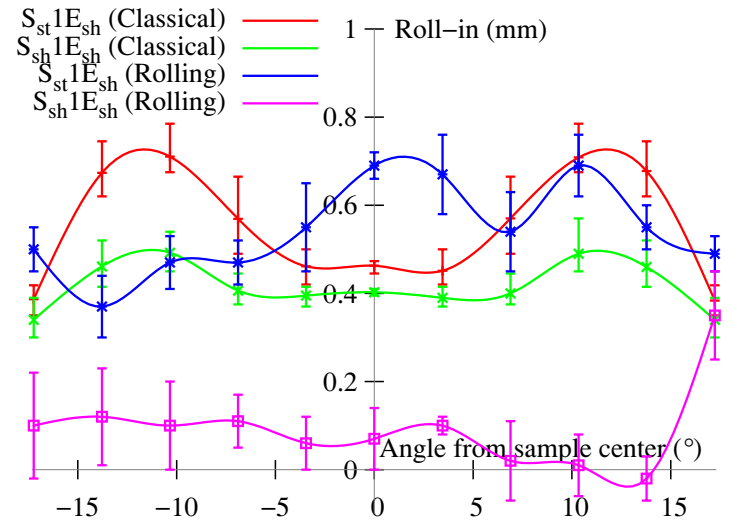

Fig. 11. Evolution of the roll-in after classical and roll-hemming
Fig.11 presents the roll-in for both configurations at the end of the multistep process by roll-hemming and classical hemming. Different evolutions are observed for each process. In classical hemming, for both configurations, a small roll-out is observed. In roll-hemming, there is a significant difference between the roll-in measured at the end of pre-hemming and hemming. The configuration $S_{s h} 1 E_{s h}$ shows a roll-in $400 \%$ less than the classical hemming, since the descent of the roller during pre-hemming causes more roll-in on the edge of the sample. For both configurations, the curves obtained during roll-hemming presents a strongly non symmetric shape. This observation highlights the fact that this process does not allow for a symmetric geometry as the classical hemming process. This phenomenon is partly due to a larger deformation of the sheet during the descent of the roller. The inverse path of the roller does not completely compensate for this phenomenon. However, like classical hemming, configuration $S_{s h} 1 E_{s h}$ stands out with a higher roll-in value for its ends, with a difference of $380 \%$ from its center. Roll-in variations can be noted along the hemmed edges, which points out the high wrinkling sensibility of this hemming technology.

\section{Conclusions}

This paper presents the development of hemming tests to complete the initial database obtained by [9] on elementary samples with the adoption of more complex geometries, combining curved surfaces and radii of curvature in the plane. The samples are firstly prestrained in order to obtain a strain history prior to flanging and hemming. The choice of the sample geometries as well as prior plastic strains is based on a survey of current geometries hemmed in automotive doors. A device has been designed to hem 
these samples both by classical and roll-hemming processes and to allow a comparison between both technologies. The purpose was to help the understanding of phenomena generated during hemming by establishing rules for predicting, from a curved surface with a radius of curvature in the plane, the roll-in and other geometric parameters such as the opening angle and the flanging height. The analysis of the results on different samples shows that it is difficult to establish such rules in such a complex multistep process. The use of numerical simulation can nevertheless predict each stage of deep drawing and hemming [10]. All these tests also provide an experimental database on the load evolution and the geometric parameters such as roll-in. Results show that the roll-in as well as the load from roll-hemming are lower than from classical hemming and that their evolutions greatly differ between the two processes.

\section{References}

1. H. Livatyali, A. Müderrisoğlu, M.A. Ahmetoğlu, N. Akgeman, G. Kinzel, T. Altan, J. Mat. Proc. Tech., 98, (2000) 41-52

2. S. Thuillier, N. Le Maoût, P.Y. Manach, D. Debois, J. Mat. Proc. Tech., 198, (2008) 226-233

3. X. Hua, Z.Q. Lina, S.H. Li, Y.X. Zhao, Mat. \& Des., 31 (3), (2010) 1410-1416

4. H. Livatyali, S.J. Larris, J. Mat. Proc. Tech., 153-154, (2004) 913-919

5. N. Le Maoût, S. Thuillier, P.Y. Manach, Exp. Mech., (2010) doi 10.1007/s11340-009-9297-7

6. H. Livatyali and T. Altan, J. Mat. Proc. Tech., 117, (2001) 262-268

7. A. Müderrisoğlu, M. Murata, M.A. Ahmetoğlu, G. Kinzel and T. Altan, J. Mat. Proc. Tech., 59, (1996) 10-17

8. H. Livatyali, A. Müderrisoğlu, M.A. Ahmetoğlu, N. Akgeman, G. Kinzel and T. Altan, J. Mat. Proc. Tech., 98, (2000) 41-52

9. C. Lange, Tech. de l'ingénieur, BM 7 866, (2008) 1-19

10. N. Le Maoût, S. Thuillier, P.Y. Manach, Mat. \& Des., (2010) doi 10.1016/j.matdes.2010.01.030 